\title{
SOBRE EL PROBLEMÁTICO CONCEPTO DE MENCIÓN IRÓNICA
}

\author{
Alberto Bruzos Moro \\ Princeton University (New Jersey, EEUU) \\ abruzos@princeton.edu
}

\begin{abstract}
Resumen
La teoría de la mención, según la cual el enunciado irónico es la mención de un contenido hacia el que el locutor expresa además una actitud reprobatoria, es superada por la perspectiva de Ducrot, basada en su noción de polifonía, en cuyos términos puede ser formulada de una manera menos equívoca que en los propios términos de Wilson \& Sperber. El enfoque polifónico de la ironía trasciende también la teoría de la simulación (pretense theory), la cual supone que el irónico simula (is pretending) que es un ignorante, pero de hecho confia en que las personas a quienes va dirigida la ironia adviertan el simulacro y, así pues, su actitud negativa hacia el hablante y el enunciado imitados.
\end{abstract}

PALABRAS CLAVE: polifonía, mención, ironía, mención irónica, relevancia, discurso, actitud.

\begin{abstract}
The mention theory of irony, which argues that the ironist uses his utterance to mention its literal meaning expressing a derogative attitude toward it, is excelled and comprehended by Ducrot's perspective based in his notion of polyphony. The polyphonic account of irony trascends also the pretense theory, according to which the ironist pretends to be an injudicious person, but is actually intending the persons to whom the irony is addressed to discover the pretense and thereby his negative attitude toward the speaker and the utterance.
\end{abstract}

KEY WORDS: Polyphony, Mention, Irony, Echoic utterance, Relevance, Discourse, Attitude.

Este artículo revisa una de las propuestas más aceptadas para explicar la ironía dentro del ámbito de la pragmática, la teoría de la mención de Wilson y Sperber. En concreto, se intenta demostrar que el concepto mención, tal como es definido por los citados autores, resulta problemático debido por un lado a las connotaciones ligadas al término, que hacen que muchos de sus críticos yerren al entenderlo de manera estricta, relacionándolo exclusivamente con la reproducción de una enunciación anterior; y, por otro lado, a causa de la manera tan amplia en que Wilson y Sperber conciben realmente la mención (desde la cita propiamente dicha al eco de una proposición o significado), lo que prácticamente iguala sus condiciones a las de cualquier otro tipo de discurso (en el cual el enunciado es también el significante de un significado). Lo esencial de la enunciación irónica no parece ser sólo, ni ante todo, su referencia a otra enunciación o contenido, sino que hay que entenderla más bien en términos de inadecuación al contexto (Attardo), o de una estructura argumentativa contradictoria que exige del intérprete la comprensión de una organización no literal de los roles o posturas en conflicto. Es en este punto donde el análisis pragmático polifónico de Ducrot, con su desdoblamiento del locutor en varios enunciadores o puntos de vista, cuya opinión no tiene por qué coincidir con la de la persona que habla, se muestra como un medio de descripción más efectivo del lenguaje irónico y, además, capaz de comprender no sólo 
la perspectiva de Wilson y Sperber, sino también la de la teoría de la simulación (pretense theory) de Clark y Gerrig, que por lo demás prácticamente duplica su esquema conceptual bajo una terminología diferente. El artículo concluye evaluando las ventajas que presenta el enfoque común a las tres teorías consideradas (polifonía, mención y simulación), teniendo en cuenta aquellos aspectos de la ironía a los que da especial relevancia y que una descripción tradicional dejaba en un segundo plano, así como preguntándose hasta que punto, de acuerdo con la teoría de la relevancia, el eco irónico de Wilson y Sperber sería un tipo de discurso sometido a principios pragmáticos que se siguen de manera convencional, y no el resultado natural de la manera de funcionar de nuestro sistema cognitivo.

\section{La teoría de la mención irónica}

Wilson y Sperber conciben la ironía como un tipo de enunciación. En concreto, "una variedad de enunciación ecoica [echoic utterance], que se usa para expresar la actitud del hablante hacia la opinión de la que hace eco" (1992: 59). Así, interpretar un enunciado irónicamente no supone sustituir el significado literal "anómalo" por otro figurado, sino advertir que el locutor no usa directamente el significado literal: lo menciona para expresar una actitud hacia él (Jorgensen, Miller y Sperber, 1984: 115).

La controversia en torno a esta teoría recae en la definición de la mención o eco irónico. Por un lado, se objeta que no todas las enunciaciones irónicas se corresponden con una mención propiamente dicha — entre otros, Kerbrat-Orecchioni (1980: 123), Clark y Gerrig (1984: 123), Williams (1984: 127), Attardo (2000: 805)—. Sin embargo, hay que decir a favor de Wilson y Sperber que ellos no entienden la ironía como la mera cita o referencia de un enunciado particular. De hecho, son bastante claros al señalar en qué sentido la ironía consiste en una mención.

Para ello, empiezan por distinguir las citas directas, en las que el enunciado citado se repite literalmente, de las indirectas, en las que no se reproducen las palabras exactas sino sólo el significado. La ironía es una variedad de cita indirecta, la mención de una "proposición", un "significado" o un "pensamiento". Ahora bien, las citas indirectas se usan al menos con dos fines distintos: pueden representar de manera objetiva el contenido del enunciado original, o pueden expresar además la actitud del locutor hacia dicho contenido. Este segundo tipo de cita indirecta recibe el nombre de eco o enunciación ecoica (Wilson y Sperber, 1992: 58-59).

Tomemos el ejemplo de un hombre $(\mathrm{L})$ que habla a su socio $(\mathrm{R})$ de uno de sus empleados, el cual acaba de estafarles.

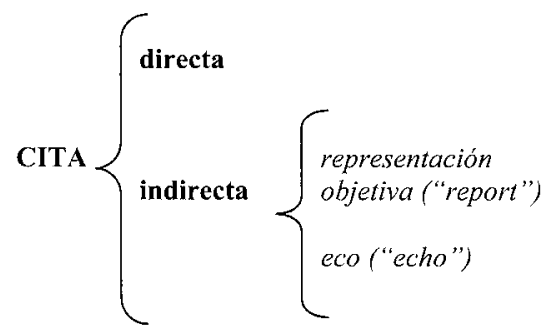

(1) Como tú dijiste: "es un hombre honrado".

(2) Tú mismo destacaste su honradez.

(3) Ya, un hombre honrado. 
Los ecos son menciones encubiertas, presentadas como enunciaciones del propio locutor. Además, en muchas ocasiones ni siquiera remiten a una enunciación anterior citada, sino únicamente a una idea o un tipo de discurso.

Los ecos no tienen verbo introductor ni están articulados sintácticamente como oraciones subordinadas [en contraste con (1) y (2)]. En algunos casos [...] parecen, a primera vista, afirmaciones del hablante, pero el contexto demuestra, con mayor o menor claridad, que no lo son, que el hablante está repitiendo lo que dijo (o lo que hubiera dicho) otro en tal situación, y añadiéndole una resonancia o deformación intencional. [...]

Los ecos no tienen por objetivo principal contar lo que alguien dijo; su función en el discurso es evocar un texto preexistente, $o$, a veces, un texto posible, y mostrar alguna actitud ante ese texto (Reyes, 1994: 11).

Puesto que el eco cita un contenido o pensamiento, éste "puede no haber sido expresado en ninguna enunciación; puede no atribuirse a ninguna persona en particular, sino sólo a un tipo de persona, o a la gente en general; puede ser una mera aspiración o norma cultural" (Wilson y Sperber, 1992: 60).

Pero aún hay que establecer una última precisión para alcanzar la ironía: no todos los ecos son irónicos, sino sólo aquellos en los que la actitud expresada es de desaprobación (ib.: 59-60).

Así, L puede usar (3) Ya, un hombre honrado como eco de la opinión de R sobre su empleado, tanto para darle la razón como para mofarse de él irónicamente. Por tanto, según Wilson y Sperber, la interpretación de (3) en clave irónica puede analizarse en dos percepciones: por un lado, advertir que se trata de un eco; por otro, reconocer el tipo de actitud (negativa) expresada por medio de él.

En definitiva, las enunciaciones irónicas "son menciones ecoicas implícitas de un significado, en las que se transmite una actitud derogatoria hacia el significado que se menciona" (Sperber, 1984: 131).

Ahora bien, ¿cómo se distingue una enunciación ecoica irónica como tal? Esto es, por un lado, ¿cómo se sabe que la enunciación de (3) tiene por objetivo principal mostrar una actitud hacia su significado y no únicamente enunciarlo? $\mathrm{Y}$, por otro lado, ¿cómo se sabe que dicha actitud es negativa y, por tanto, irónica?

La clave está en la siguiente observación de Attardo, siempre que donde él dice ecoico se precise irónico.

Es necesario usar pistas contextuales para decidir si un enunciado es ecoico [irónico] o no. [...] El único factor en el contexto de la enunciación que puede identificarla como ecoica [irónica] es que el enunciado sea de algún modo inadecuado o bien al contexto o bien al conjunto de creencias que el oyente atribuye al hablante (2000: 806 ).

Obviamente, para que (3) sea interpretado como un eco, lo decisivo es reconocer el vínculo que mantiene con la opinión de $\mathrm{R}$, su carácter de cita implícita o indirecta. Mientras que lo que determina el criterio de si resulta o no adecuado a la situación de discurso, es en realidad el tipo de actitud transmitida: si ésta coincide con el significado (con el asentimiento explícito), o bien si el enunciado ha de interpretarse de forma irónica (como polémica o burla implícita). 
Pero todavía se puede hilar más fino: para percibir la ironía del enunciado no es necesario reconocerlo como eco o mención, sino únicamente advertir su voluntad discordante o contradictoria. De hecho, es posible ver en (3) el eco de una opinión sin percibir su carácter irónico. Basta con cambiar el contexto de interpretación por uno que, en principio, concuerde con el asentimiento: por ejemplo, si el intérprete ignora que el empleado ha estafado a su empresa. O bien, al contrario, se puede percibir la ironía de (3) sin advertir que se trata de un eco de la opinión de R: por ejemplo, si se conoce el contexto apropiado (la estafa) y se relaciona (3) con él, éste sólo puede ser interpretado de modo irónico, aunque no necesariamente se reconozca la relación (de mención o eco) entre el enunciado y la opinión de $R \mathrm{y}$, en tal caso, no sea posible adscribir a una víctima la burla irónica.

De ahí que Attardo observe que reconocer el enunciado como mención es un paso ulterior (yo diria independiente) a reconocer su "inadecuación contextual", y, de hecho, innecesario para advertir la ironía: la "inadecuación voluntaria" es el criterio realmente necesario y suficiente. "La mención sólo refuerza la intención irónica" (ib.: 807).

Del mismo parecer es Kerbrat-Orecchioni. Según ella, su visión de la ironía como tropo no es incompatible con la teoría de la mención. Todos los enunciados irónicos suponen una inversión semántica o ilocutiva (un tropo), mientras que sólo algunos de ellos cumplen además la condición de ser una cita implícita.

Si la ironía es un eco, no todos los ecos son necesariamente irónicos. ¿Cuál es el rasgo específico del eco irónico? Éste radica en el hecho de que citando a otro locutor (L1), el locutor irónico (L0) toma el máximo de distancia con respecto a los contenidos citados, y da a entender que él piensa de un modo distinto, del modo opuesto. Así pues, la visión de la ironía como cita no hace más que añadir una propiedad suplementaria al fenómeno tal como ha sido descrito (es decir, en términos de inversión semántica) (1980: 122).

En consecuencia, Kerbrat-Orecchioni propone distinguir dos tipos de ironía: la ironía citativa y la no citativa. Lo común a ambas es el desdoblamiento del locutor, "correlativo al desdoblamiento semántico que constituye la ironía" (ib.). Cuando además existe una cita o mención, ésta aporta la propiedad de indicar la víctima de la ironía: "el locutor citado, a quien se responsabiliza del contenido literal" $(i b$. $)$.

Si Attardo y Kerbrat-Orecchioni relegan la mención a un papel secundario para definir la ironía, destacando en contrapartida que ésta consiste en una enunciación inadecuada $u$ opuesta al contexto, Reyes trata de equilibrar ambas propiedades.

La ironía es una cita porque el hablante repite o se hace eco de una proposición ajena, que proviene de un enunciado inmediato, o de un lugar común, o que representa lo que se suele decir en ciertas situaciones, o incluso lo que se podría decir: el hablante repite la proposición pero la aplica a un estado de cosas contrastante, volviéndola inadecuada, chocante. El desajuste entre el contenido de la expresión y la situación que se comenta con ella nos obliga a entender otra cosa distinta de lo dicho literalmente, procedimiento de interpretación que aplicamos, en general, a las figuras (1994: 51).

De acuerdo con Reyes (2002: 90), una enunciación irónica como (c) tendría la siguiente estructura pragmática: 
a) comentario explícito positivo sobre la situación, el cual resulta incongruente: "está claro para mis interlocutores que no puedo decirlo seriamente".

b) comentario implícito negativo y congruente con la situación.

Este análisis, que en principio recuerda al modelo del tropo, no supone sin embargo la sustitución de $a$ ) por $b$ ).

La estructura del proceso es básicamente la que acabo de esbozar: conflicto de significados interactuantes para evaluar una situación. [...]

La ironía surge de la interacción entre ambos significados $(i b .: 90 ; 93)$.

Así, pues, Reyes apuesta por lo que Hutcheon denomina carácter inclusivo de la ironía.

El significado irónico es simultáneamente doble (o múltiple), y por ello no es necesario de hecho rechazar un significado "literal" para llegar a lo que normalmente se llama significado "irónico" o "real" del enunciado. [...] Ambos, lo dicho y lo no dicho, forman juntos una tercera significación, y esto es lo que debería denominarse con más precisión significado "irónico" (Hutcheon, 1994: 60).

Por el contrario, para Kerbrat-Orecchioni, más fiel a la concepción retórica, si bien "una secuencia irónica se presenta como un significante único al que se ligan [...] dos niveles semánticos" (1977: 134-135), la ironía, como tropo, consiste siempre en la subordinación del contenido explícito al implícito. Esto es, el significado primordial del enunciado irónico es la inversión de su significado literal, el cual persiste únicamente como un "contenido connotado"'.

Volviendo a Reyes, el sentido irónico b) ni siquiera consiste siempre en la mera inversión del contenido explícito a).

Los enunciados irónicos suelen tener muchas resonancias, no solamente un significado nítido que, además, deba ser exactamente opuesto al expresado o la negación del expresado. [...]

Son pocas las ironías que surgen de inversiones del significado literal [...]. De hecho, [...] el significado implicado no es siempre fácil de formular de manera inequívoca (2002: 92).

Con todo, a) es necesariamente una cita o eco de una actitud concreta, en unos casos ligada a un locutor al que remite, en otros, libre de tal referencia, es decir, la cita de un enunciado meramente posible. La postura de Reyes no puede ser más clara.

Creo, con Sperber y Wilson, que en todas las ironías se percibe lo que ellos llaman un eco, y que yo llamaré más simplemente una cita [...] de una frase, reconocible por su forma y su contenido, que se caracteriza por expresar, sobre todo en la conversación, apetencias o expectativas normales de la comunidad, más o menos contradichas por una situación determinada, que queda evaluada negativamente. No existe una clase de ironía no citativa (ib.: 105). 
En resumidas cuentas, de acuerdo con Reyes, la ironía conserva por un lado el carácter incuestionable de eco o cita, pero por otro lado se origina mediante un contraste entre el contenido citado y la situación de discurso. "La expresión irónica es una expresión deliberadamente mal usada: se aplica mal a la situación" (Reyes, 1994: 54). Lo que, de hecho, indica que no está siendo usada, sino en realidad mencionada irónicamente.

En otras palabras, la mala aplicación deliberada del enunciado a la situación de discurso deroga su uso e indica su carácter alternativo de cita irónica. Y es necesario subrayar la especificidad irónica de la mención o cita, pues si bien de manera general ésta se opone al usso, no sólo el uso es neutro (no irónico), sino que asimismo lo es el eco (mención, cita) de una proposición hecho con objetividad o transmitiendo una actitud positiva hacia ella. Lo que reincide en la idea de que el criterio para determinar si un enunciado es una mención o cita indirecta ha de ser independiente del criterio para determinar si la enunciación es irónica. Aunque, a posteriori, resulte que (según el planteamiento de Wilson y Sperber y Reyes) toda enunciación irónica sea por definición un eco. Los dos criterios combinados por Reyes, inadecuación contextual y carácter de cita, no discurren pues por la misma senda ni conducen a la misma conclusión. Por lo demás, está claro cuál de los dos concluye en la ironía. Gráficamente:

El enunciado, en relación con cl comexto, resulta

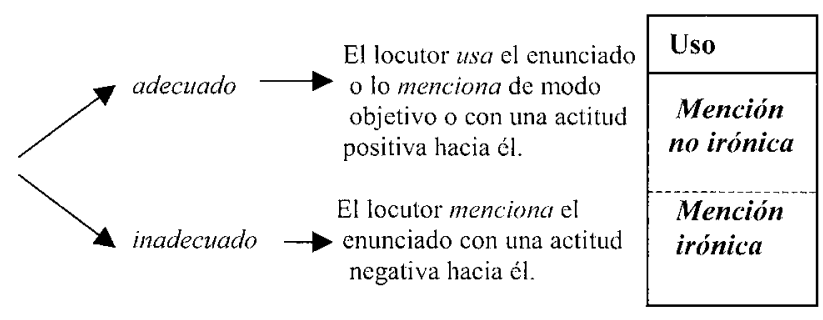

Hay que decir a favor de quienes se oponen confusamente a la presente teoría que son sus propios defensores lo que en parte siembran la confusión al describir la peculiaridad del enunciado irónico en términos de mención o cita. De acuerdo con el sentido amplio que le dan a estas nociones, desde la cita propiamente dicha al mero eco de una proposición o significado, para evitar malentendidos no deberían dar a entender que advertir la ironía de un enunciado requiere reconocerlo como un eco negativo, como si ésta fuera una condición previa y la mención, por tanto, una marca de ironía. Al contrario, deberían subrayar que, por definición, advertir que un enunciado es irónico es lo mismo que reconocerlo como un eco negativo.

Volviendo a (3), ya hemos dicho que lo que determina su sentido irónico no es en definitiva que se advierta su carácter de cita o de mención ecoica, sino la relación discordante entre el enunciado y su contexto. Por consiguiente, en ausencia de otras marcas (entonación, gestos, etc.), la señal decisiva de que un enunciado es irónico procede de su relación voluntariamente incongruente o contradictoria con el contexto, mientras que el hecho de que se trate de la cita de otra enunciación (concreta o sólo posible) es secundario y, cuando se da, únicamente determina y señala el objeto o víctima de la ironía.

Con todo, lo anterior supone más bien una alternativa que una refutación de la teoría de la mención. Pues ésta, en el fondo, no viene a decir que la cita o eco sea una marca o medio 
material para señalar la ironía de una enunciación. En todo caso, es la propia enunciación irónica, como hecho consumado, la que se describe como "mención ecoica depreciativa", por lo que la ironía ha de entenderse como una relación peculiar entre el locutor y su enunciado: de mención, y no de uso. Es más, no de cualquier tipo de mención, sino de una mención distante, negativa o burlesca. El enunciado irónico no transmite su contenido: lo menciona, es la representación implícita (el eco) de un pensamiento del que el locutor se disocia.

[El locutor irónico] hace eco de un pensamiento que atribuye a otra persona, a la vez que se disocia de él, yendo desde un leve ridículo a un encono salvaje. [...]

Todo enunciado puede entenderse de dos maneras completamente distintas: como expresión de la propia opinión del hablante, o como eco o informe de una opinión atribuida a otra persona (Wilson y Sperber, 1992: 60; 62).

La ironía produce una alteración en el valor asertivo de un enunciado: el hablante afirma dos cosas a la vez, por lo menos, y de una de ellas, la explícita, no se hace cargo, del todo o en parte (Reyes, 2002: 105).

Disociación, descargo de responsabilidad, son términos que parecen sacados de la teoría polifónica del discurso de Ducrot. De hecho, la teoría de la mención puede asimilarse al marco más amplio de la polifonía. Así, decir que el locutor usa el enunciado equivale a decir que se responsabiliza de su sentido, que se presenta como origen único y fidedigno del punto de vista expresado por él. Mientras que mención irónica no es más que una denominación bastante equívoca para aquellos casos en los que el locutor presenta un punto de vista (un enunciador) distinto del propio y al que se opone de manera implícita. De hecho, el mismo Ducrot (1984: 214-215), quien presenta su teoría como una versión de la de Sperber y Wilson, rechaza el término mención por su ambigüedad.

\section{La ironía como enunciación polifónica}

Según Ducrot, la enunciación irónica es un tipo de enunciación polifónica. En concreto, la enunciación es irónica cuando el locutor introduce en ella un punto de vista diferente del propio, del que se disocia y se burla implícitamente.

La polifonia se caracteriza por la confrontación, en el mismo enunciado, de varias perspectivas que se yuxtaponen, se superponen o se responden. Supone, por tanto, "una concepción teatral de la enunciación [...]. La enunciación aparece como la puesta en escena de diferentes actitudes, independientes las unas de las otras o que dialogan entre ellas" (Ducrot, 1989: 189-180).

Obviamente, no toda enunciación polifónica es irónica. Ducrot (1984: 200-214) distingue dos tipos de polifonía:

1) La "doble enunciación", en la que un enunciado presenta marcas semánticas (deícti$\cos$ ) de primera persona que remiten a dos locutores diferentes. Es el caso del estilo directo ("Juan me ha dicho: "Me duele mucho»"), los ecos imitativos (A: "Me duele", B: "Me duele, me duele; no creas que me das lástima") o el discurso hipotético ("Si alguien me dijera: me duele..."). 
El sentido del enunciado atribuye a la enunciación dos locutores distintos. [...] Desde el punto de vista empírico, la enunciación es obra de un solo sujeto hablante, pero la imagen que el enunciado da de ella es la de un intercambio, un diálogo o incluso una jerarquía de manifestaciones (ib.: 203).

2) La enunciación en que, en lugar de existir dos locutores identificados semánticamente (mediante los correspondientes deícticos), se produce un desdoblamiento implícito entre el locutor único y otros entes discursivos subordinados a él y a los que Ducrot denomina enunciadores.

Llamo enunciadores a los orígenes de los diferentes puntos de vista que se presentan en el enunciado. No son personas sino "puntos de perspectiva" abstractos. El locutor mismo puede ser identificado con alguno de estos enunciadores, pero en la mayoría de los casos los presenta guardando cierta distancia frente a ellos (Ducrot, 1990: 20).

En la "doble enunciación", la polifonía se origina por la fusión de dos enunciaciones distintas, con sus respectivos centros de referencia interna; normalmente, una se inscribe en la otra y se le subordina. La polifonía es una confluencia de voces: los locutores de las enunciaciones fusionadas no coinciden, las marcas de primera persona de cada una de ellas se refieren a seres distintos. Puesto que se trata de enunciaciones distintas, cada una indica un origen diferente. Incluso cuando el locutor de ambas apunta al mismo ser empírico, el mismo sujeto hablante, quien por ejemplo se cita a sí mismo ("Entonces, yo le dije: "Me duele»"), persiste la escisión en dos seres discursivos (dos locutores): el yo-aquí-ahora que cita y el yo-alli-entonces citado (Berrendoner, 1981: 164).

Sin embargo, los enunciados polifónicos cuyo sentido presenta varios enunciadores suponen una sola enunciación y, por consiguiente, un único locutor. Él es el responsable del sentido, de organizar los puntos de vista o actitudes de los enunciadores, como el autor de una miniatura dramática. No existen, por tanto, marcas semánticas de primera persona referidas a otros locutores.

En consecuencia, los enunciadores no son los sujetos de ningún acto de palabra. Son, más bien, puntos de vista, actitudes, orientaciones discursivas, "centros de perspectiva" (término que Ducrot toma de Genette), difíciles de definir (y a veces también de percibir) de manera precisa (Ducrot, 1984: 208-214). Tal como yo lo veo, su función es manifestar, en el marco de un mismo enunciado, orientaciones argumentativas o tipos de discurso en confrontación, los cuales pueden ser asimilados o no al locutor, esto es, con los cuales el locutor puede comprometerse o disputar en mayor o menor grado. Dicho de manera un tanto simple, el locutor puede alinearse $(A)$ con o $(B)$ contra la orientación o el discurso indicados por un enunciador particular, o bien $(C)$ mantener una postura neutral u objetiva al respecto.

(A) Como consta en la Declaración de los Derechos Humanos, la tortura es una práctica aberrante.

(B) No es cierto que haya circunstancias que justifiquen que se recurra a la tortura.

(C) En algunos países, la tortura es un recurso policial. 
Dado que solamente una enunciación entra en juego y, por tanto, todas las marcas semánticas de deixis la señalan a ella y se organizan tomándola por único punto de referencia, esta polifonía es mucho más sutil y compleja que la originada por una "doble enunciación".

Por supuesto, en la lengua existen unidades semánticas y estructuras gramaticales destinadas a manifestarla. Por ejemplo, en $(A)$ el enunciador (La tortura es una práctica aberrante) es atribuido de manera explícita (Como consta en...) a una determinada entidad discursiva (en este caso un documento, la Declaración de los Derechos Humanos), a cuyo punto de vista se suma el locutor. Mientras que en $(B)$ el locutor rechaza un enunciador (Hay circunstancias que justifican que se recurra a la tortura) implícito en la estructura pragmática de la "negación polémica" No es cierto que 2 .

Pero si bien siempre hay algún índice material que la marque (como los vistos o, por ejemplo, la entonación o, en la lengua escrita, las comillas, la cursiva o algún procedimiento equivalente ${ }^{3}$ ), puede ser que no se trate de un procedimiento propiamente lingüístico, de modo que a menudo la única pista es la connotación de un modo de discurso distinto del que, de manera más o menos coherente, sostiene el locutor. Esta disonancia puede ser tan leve que pase desapercibida y que, erróneamente, se asimile la perspectiva al responsable central del discurso.

Hay una anécdota de Boris Pasternak que ilustra oportunamente este punto. El poeta ruso se queja en una carta de que no se hubiera entendido el uso polifónico de algunos materiales que había introducido en sus poemas El año 1905 y El teniente Schmidt, y que por consiguiente se le hubiera imputado la responsabilidad directa (como locutor) de su banalidad y su rancio lirismo.

El autor [dice el propio Pasternak], haciendo uso de materiales documentales de aquella época, los trató y desarrolló sin romanticismo, de manera altamente realista, considerando como fin de ambos poemas pintar un cuadro de época, costumbrista. [...] Por eso, cuando, con su alto nivel y dramatismo, los documentos mostraban rasgos de limitación, de redundancia política, o eran de algún modo ridículos, el autor los trasladó al poema, en vista del proyecto y de la intención final, convencido de que su retórica se delataría por sí misma. Era imposible proveerlos de comentarios. Pero cierta ironía del capítulo III, que en la opinión del autor era absolutamente evidente (se trata del tono de la fanfarronería

2 Cf. Ducrot (1984: 219-225) para un análisis polifónico detallado de la negación.

3 Hay muchas variaciones posibles. Por ejemplo: $\left(A^{\prime}\right)$ Como consta en la Declaración de los Derechos Humanos, "la tortura es una práctica aberrante". ( $A$ ") Como consta en la Declaración de los Derechos Humanos, la tortura es una práctica aberrante.

Obsérvese que la asepsía del ejemplo $(C)$ depende no sólo de la ausencia de términos axiológicos o evaluativos, sino también, en buen grado, de la de este tipo de marcas. Así, ya no serían tan objetivos: ( $\left.C^{\prime}\right)$ En algunos países, la tortura es un lamentable/miserable/ inevitable/ eficaz recurso policial. En algunos países, la tortura es una artimaña/ treta/ argucia/ prerrogativa policial. Como tampoco: ( $\left.C^{\prime \prime}\right)$ En algunos países, la tortura es un recurso policial. O bien: ( $\left.C^{\prime \prime}\right)$ En algunos países, la tortura es "un recurso policial".

A lo que habría que añadir la dificultad de situar argumentativamente el discurso del locutor y, en relación con él, la enunciación particular. Por ejemplo: En algunos paises, la tortura es una artimaña policial. ¿Es artimaña un término simpático o antipático para el locutor? Pues artimaña lo mismo puede comportar una connotación negativa (como "artificio o astucia para engañar a alguien", DRAE), que una connotación positiva (pues como "astucia" o "maña" minimiza la gravedad de la tortura, la cual es obviamente bastante peor que eso). La respuesta depende en buena medida de la posición discursiva general del locutor; esto es, de las opiniones, creencias, actitudes, simpatías y antipatias (en este caso, hacia la policía y la tortura) coherentes con su discurso y, por tanto, implicitas en él 
intelectual), al no haber sido explicada quedó incomprendida por la mayoría e incluso por ciertas personas de alta inteligencia receptiva, como Tsvietáieva y Mayakovski ${ }^{4}$.

La ironía es precisamente una enunciación polifónica cuyo locutor polemiza implícitamente con al menos un enunciador o punto de vista. El locutor presenta el enunciado "como si expresara la posición de un enunciador $E$, posición que por otra parte se sabe que el locutor L no toma bajo su responsabilidad y que, más aún, la considera absurda. Sin dejar de aparecer como el responsable de la enunciación, $\mathrm{L}$ no es homologado con $\mathrm{E}$, origen del punto de vista expresado en la enunciación" (Ducrot, 1984: 215).

Es fundamental que la perspectiva de E no sea desaprobada o rechazada por L de manera explícita, es decir, semánticamente (como parte del significado oracional).

La posición absurda es directamente expresada (y no transmitida) en la enunciación irónica, y al mismo tiempo no es puesta a cargo de L [...]. En la ironía es esencial que L no ponga en escena a otro enunciador, $E^{\prime}$, quien por su parte sostendría el punto de vista razonable. Si $\mathrm{L}$ debe marcar que él es distinto de $\mathrm{E}$, lo hace de una forma muy diferente, recurriendo por ejemplo a una evidencia situacional, a entonaciones particulares, y también a ciertos giros especialmente irónicos (como "iMuy bonito!", "¡Casi nada!", etc.) (ib.: 215-216).

Tal como la describe Ducrot, la enunciación irónica se asemeja a los chistes cuyo autor "pone en escena" a un personaje que dice algo absurdo o ridículo. De hecho, el mismo Ducrot la define como un tipo de enunciación humorística, "en que el punto de vista absurdo es atribuible a un personaje determinado, que se busca ridiculizar" (1990: 21), y señala asimismo la correlación locutor-enunciador/ autor-personaje (1984: 209).

Mediante este procedimiento, el autor/ locutor significa el contenido o pensamiento del enunciado y, además, indica de manera implícita su actitud hacia él ("Esto es absurdo") y hacia quien se identifique con el personaje/ enunciador ${ }^{5}$.

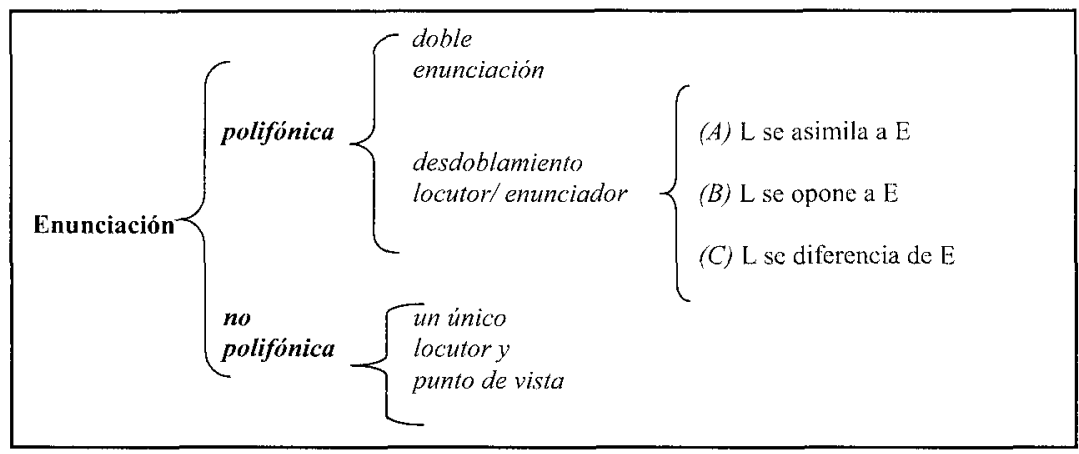

4 B. Pasternak, R. M. Rilke. \& M. Tsvietáieva: Cartas del verano de 1926, Grijalbo-Mondadori, Barcelona, pág. 287.

5 No obstante, el análisis de la polifonía y la ironía del chiste es más complejo que el de una enunciación ordinaria, pues se trata de una enunciación (la del personaje) enunciada (por el autor), en la que por tanto se solapan dos niveles de sentido (de intención del locutor). 
En definitiva, atendiendo al cuadro superior, la enunciación irónica es una enunciación híbrida, lingüísticamente (explícitamente) similar a la categoría $(A)$, pero pragmáticamente (implícitamente) equivalente a la categoría $(B)$.

De la oposición polifónica explícita $(B)$ se diferencia por la ausencia de marcas semánticas en el enunciado que indiquen la oposición entre $\mathrm{E}$ y $\mathrm{L}$. Volviendo a nuestro viejo ejemplo de la estafa:

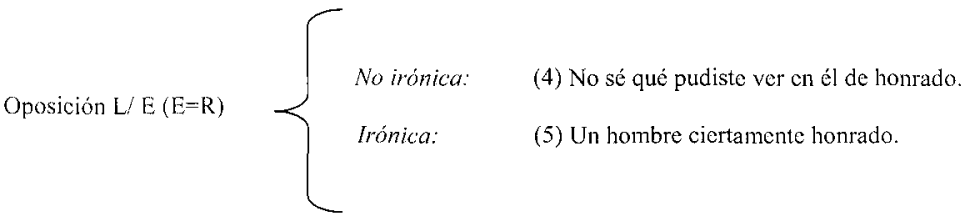

En ambos casos, la polifonía se concentra en el calificativo honrado (discurso de $\mathrm{R}$ ), al que L se opone explícitamente en (4): No sé qué..., e implícitamente en (5): dada la situación de discurso (la estafa y, quizá también, la mala opinión, ya previamente manifiesta, que puede ser que tuviera $\mathrm{L}$ del estafador). La ironía conlleva además un efecto implícito de mofa, que la oposición polifónica neutra $(B)$ puede expresar sólo de manera explícita: ES RIDICULO QUE lo tomaras por un hombre honTado, HAY QUE SER TONTO PARA tOmarlo por un hombre honrado, etc.

Por otra parte, la enunciación irónica se diferencia de la asimilación genuina de $\mathrm{L}$ a $\mathrm{E}$ (A) por la presencia de marcas no lingüísticas, sino de naturaleza discursiva, que, de manera implícita, indican precisamente lo contrario: la polémica entre ambas perspectivas. Estas marcas son inherentes a la propia enunciación, a la "gestualidad locutoria" (Berrendoner, 1981: 177) en que consiste: la puesta en escena del enunciado en una determinada situación de discurso, originando un signo complejo (enunciado y contexto). Así, basta con cambiar la situación de discurso de (5) —el empleado ha demostrado ser un trabajador modélico que antepone el beneficio de su patrón y su empresa a la salud y el bienestar propios- para que se mantenga la asimilación de L a $\mathrm{E}$ semánticamente expresa en el enunciado. Por lo demás, incluso en este caso la polifonía persiste debido al ciertamente, unidad que supone un enunciador distinto de L, cuya opinión suscribe éste.

Siendo estrictos, la ironía no siempre consiste en un conflicto nítido entre la perspectiva del locutor y la expresada por el enunciado. En el caso de la ironía inestable (Booth) o heuristica (Muecke) la verdadera posición del primero resulta voluntariamente ambigua. Entonces la ironía permite argumentar en dos sentidos opuestos sin la necesidad de comprometerse de manera definitiva con ninguno de ellos; ya sea como maniobra defensiva, para eludir la sanción de normas sociales o discursivas (Berrendoner, 1981: 196-199), ya por la lucidez de que la propia realidad de que se habla es paradójica, de que toda opinión es relativa y de que la verdad debería ser un punto intermedio lógicamente inaccesible - de ahí que Jankélévitch (1964: 133) llame a la ironía "victoria sobre el tercio excluso".

Presentado como el responsable de una enunciación donde los puntos de vista no son atribuidos a nadie, el locutor parece entonces exterior a la situación de discurso: definido por la simple distancia que establece entre sí mismo y su habla, se coloca fuera de contexto y con ello obtiene una apariencia de despreocupación (Ducrot, 1984: 217). 
En este tipo de enunciación irónica, el sentido permanece abierto. Lo que no sólo se debe a que sea imposible expresarlo en palabras, traducirlo a un "contenido irónico" neto; antes de ello, lo imposible es orientar argumentativamente el enunciado. Si bien hay una disociación entre el locutor y el enunciador (o entre varios enunciadores distintos), un conflicto entre varios tipos o universos de discurso, estos dialogan en equilibrio, sin que pueda determinarse de una vez por todas con cuál de ellos coincide la auténtica voz del locutor. El sentido de la enunciación es una "disonancia irresoluble" (Jankélévitch, 1964: 135), como en este ambiguo cumplido de Lichtenberg:

(6) Si el Papa quisiera casarse, no sabría proponerle esposa más virtuosa.

El matiz irónico lo marca la inconveniencia de la prótasis, más bien por su excentricidad que por su falsedad o por un litigio argumentativo propiamente dicho con la apódosis (pues, en realidad, el beneplácito del Papa es un argumento a favor de la virtud conyugal). Cuando alguien quiere hacer un cumplido claro, sin ambages, no recurre precisamente a una hipótesis descabellada, incluso ridícula, y además con el Papa de por medio, habiendo tan buenas alternativas: "Si mi mejor amigo/ mi hermano/ mi hijo, etc. quisiera casarse...". Esta torpeza tan flagrante (el "absurdo" del que habla Ducrot) libera al locutor de suscribir el sentido de su enunciado: "el punto de vista absurdo no es atribuido al locutor" (Ducrot, 1990: 20), e indica así la presencia de una perspectiva (un enunciador) de la que, sin llegar a oponérsele, se disocia o distancia. El cumplido sigue siendo un cumplido, pero con un matiz irónico que lo contiene, que atenúa su valor pragmático. - Además, la locución de (6) ha de imaginarse naturalmente ejecutada con una entonación irónica, una máscara de falsa estupidez o un guiño de complicidad perversa, índices externos y suplementarios de la ironía.

Es a esta clase de ironía a la que se refieren quienes, como Bozal y Kundera, ponderan su flexibilidad y tolerancia.

La ironía es el marco en el que las evidencias se impregnan de lo mejor que la modernidad posee: la capacidad de dudar (Bozal, 1999: 107).

La ironía irrita. No porque se burle o ataque, sino porque nos priva de certezas revelando el mundo como ambigüedad (Kundera, 1986: 147).

Por el contrario, la ironía estable o correctiva ataca y se burla, es un arma argumentativa cuya ambigüedad es un mero artificio. El locutor confirma sólo en apariencia el punto de vista del enunciador, al que en realidad se opone y, además, ridiculiza. Por ejemplo, el siguiente extracto de una carta en la que Gustav Mahler se dirige a su amigo Bruno Walter como si ambos compartieran la opinión (el discurso) de quienes critican al compositor.

(7) La obra entera [la Tercera Sinfonía] está, desde luego, teñida con mi deplorable sentido del humor y "aprovecha a menudo la ocasión para someterse a mi lamentable afición por los sonidos desagradables". Bastante a menudo los músicos "no se prestan la menor atención mutua, y es toda mi naturaleza morbosa y brutal la que se revela en su entera desnudez". Cualquiera sabe que no puedo pasarme sin trivialidades. Esta vez, sin 
embargo, se han franqueado los límites de lo soportable. "¡A veces se tiene la impresión de haber entrado en una tasca o en una pocilga!"

El acierto fundamental del análisis polifónico de la ironía estriba en que el enunciado irónico no se describe ya en términos tropológicos, como una transgresión seguida de una reinterpretación conciliadora. La interpretación irónica no rectifica una interpretación literal absurda, sino que el absurdo literal es una marca, entre otras, que indica la necesidad de una interpretación irónica. Ésta, por tanto, no es una resolución secundaria, sino un camino alternativo; no sustituye un sentido presente por otro ausente, sino que da sentido a las palabras presentes.

Lo que se opone, pues, no es una interpretación normal o convencional a otra ocasional e imaginativa, como sugiere la idea de reinterpretación o reconstrucción propia del tropo, manifiesta en las palabras de Searle (1979: 109): "La ironía no requiere ninguna convención extralingüística o de otro tipo". En realidad, la oposición se da entre dos patrones o modos alternativos de interpretación, dos variedades enunciativas o discursivas igualmente convencionales a las que puede recurrir el locutor, las cuales consisten en dos maneras distintas de estructurar los factores locutivos del enunciado.

No hay duda de que en el discurso irónico no es en el nivel de la lengua donde se hace la atribución de los roles [L y E] a comediantes diferentes, pero tampoco es en este nivel donde se hace, en el discurso serio [no irónico], su atribución a un comediante único (Ducrot, 1984: 219).

Así pues, la interpretación irónica no invierte un sentido ya constituido, sino que constituye uno propio, quizá "poco habitual", pero ni más ni menos conforme al discurso y sus normas que la interpretación neutra "habitual".

En definitiva, dado que no todo eco o mención implícita es irónico, sino sólo el que supone una actitud negativa del locutor hacia el contenido mencionado, parece más apropiado describir directamente la enunciación irónica de acuerdo con el compromiso que el locutor manifiesta hacia su enunciado. Así, cuando éste es obviamente nulo, el enunciado sólo puede interpretarse como un eco irónico, y no como la verdadera opinión del locutor.

La versión polifónica de la ironía conduce a una mejor comprensión de la naturaleza de lo que Wilson y Sperber definen vagamente como eco. La posibilidad de mencionar un pensamiento o contenido ajeno, incluso impersonal, que, según ellos, posibilita el discurso irónico y en parte lo caracteriza no es algo nuevo ni extraordinario, sino al contrario una consecuencia directa de la concepción saussureana del signo lingüístico. Pues, bien mirado,

\footnotetext{
6 Bruno Walter: Gustav Mahler, Alianza, Madrid, 1982. Es evidente que Mahler usa las comillas para señalar que se trata del discurso de "sus amigos, los críticos" y no del propio. Ahora bien, lo entrecomillado no necesariamente reproduce una enunciación previa determinada, como una cita o mención, sino que puede ser una mera imitación de dicho discurso. Lo importante, desde el punto de vista enunciativo, es que se trata de la expresión de un enunciador, una perspectiva representada por el locutor (Mahler). Ahora bien, ésta trasciende los límites marcados por las comillas, pues términos como deplorable o los enunciados Cualquiera sabe que no puedo pasarme sin trivialidades. Esta vez, sin embargo, se han franqueado los límites de lo soportable son directamente asimilados al locutor (Mahler), aunque no expresen su verdadera opinión sino la de sus críticos. En cualquier caso, la ironía se debe a que este enunciador o discurso es presentado globalmente como si Mahler estuviera de acuerdo con él.
} 
¿no es todo enunciado, en cuanto significante, el eco del significado al que representa? Como observa Ducrot a propósito de Bally:

La perpetua posibilidad de una separación entre el pensamiento que se tiene y el que se comunica (atribuyéndoselo o no) le parece [a Bally] una consecuencia necesaria de la naturaleza del signo. En la medida en que éste, según Saussure, comporta a la vez un significante y un significado, y por otra parte en la medida en que el significado, según Bally, es un pensamiento, la libertad que tenemos de elegir entre los signos implica la libertad de elegir un pensamiento: el tesoro de frases de que disponemos gracias a la lengua es al mismo tiempo una galería de máscaras o un guardarropa de disfraces que permiten adoptar una multitud de personajes distintos -e, incluso si el personaje elegido se conforma al pensamiento "real", es todavía un personaje. [...] Uno no comunica "su" pensamiento, uno comunica "un" pensamiento (1989: 173).

Lo importante, prosigue Ducrot, es que la disociación entre el locutor y el enunciador no es un fenómeno accidental y marginal. Al contrario, se desprende de la naturaleza misma del signo lingüístico, aparte de que pueda manipularse ( $\mathrm{y}$, de hecho, se manipule) con fines significativos.

Esto implica que uno no comunica directamente su propio pensamiento, sino solamente un pensamiento que, por lo demás, puede conformarse o no al suyo. La distinción entre locutor y enunciador no es más que el aspecto más evidente del carácter esquizofrénico de toda comunicación ( $i b:$ 174).

En sentido estricto, pues, todo enunciado es la "mención" de un "pensamiento"; lo que varía es el grado de adhesión a él que el locutor manifiesta.

Recapitulando, aunque la concepción del discurso irónico de Wilson y Sperber y la de Ducrot coinciden en sus líneas generales, el modelo polifónico del autor francés supone una terminología más apropiada y menos problemática que la noción de mención irónica por dos razones fundamentales:

1) Si la mención ha de entenderse en general como el eco o representación de una "proposición", un "significado" o un "pensamiento", entonces todo significante sería una mención de su significado, de modo que el término mención irónica vendría a significar literalmente signo irónico.

2) Si lo que caracteriza a la mención irónica no es por tanto su naturaleza de eco, sino más bien el hecho de que además indica la actitud negativa del hablante hacia el pensamiento "mencionado", ¿no sería mejor recurrir a términos como disociación o distanciamiento, propios de la concepción polifónica de la ironía, y no al de mención, que nombra el fenómeno atendiendo a una característica ciertamente suya, mas como se ha mostrado contingente?

\section{La teoría de la simulación ("pretense theory")}

Otro tanto puede decirse de la teoría de la simulación ("pretense theory of irony") de Clark y Gerrig (1984), que no obstante es presentada como una alternativa a la teoría de la mención de Wilson y Sperber. 
En principio, ambas perspectivas coinciden en que quien ironiza no usa una proposición para comunicar la contraria; sin embargo, Clark y Gerrig (1984: 121) no oponen el uso a la mención, sino a la simulación ("pretense").

La teoría de la simulación puede describirse tal como sigue. Supongamos que $\mathrm{H}$ habla a $\mathrm{D}$, el destinatario primario, y a $\mathrm{D}^{\prime}$, presente o ausente, real o imaginario. Cuando habla irónicamente, $\mathrm{H}$ simula ser $\mathrm{H}^{\prime}$ hablando a $\mathrm{D}^{\prime}$. Lo que dice $\mathrm{H}^{\prime}$ es, de algún modo u otro, patentemente absurdo o insensato, digno de un "juicio hostil o derogatorio o de un sentimiento como la indignación o el enfado" (Grice, 1978:124 [citado por los propios Clark y Gerrig]). La intención es que $\mathrm{D}^{\prime}$, por su ignorancia, no reconozca la simulación y piense que $\mathrm{H}$ habla en serio. Sin embargo, D, como parte del "círculo privado" (usando la expresión de Fowler), ha de darse cuenta de todo: la simulación, la insensatez de $\mathrm{H}^{\prime}$, la ignorancia de $\mathrm{D}^{\prime}$, y en consecuencia la actitud de $\mathrm{H}_{\text {hacia }} \mathrm{H}^{\prime}$, $\mathrm{D}^{\prime}$ y lo que dice $\mathrm{H}^{\prime}$. $\mathrm{H}^{\prime}$ y $\mathrm{D}^{\prime}$ pueden ser individuos reconocibles [...] o tipos de gente (ib.: 122).

En realidad, la diferencia entre ambas teorías es meramente superficial. La explicación de fondo del fenómeno es la misma, aunque con distintas palabras. Así, pues, totalmente de acuerdo con Barbe: "Ambos enfoques son complementarios [...] y no difieren mucho en su descripción de la ironía" (1995: 50-51), y con Williams: "La teoría «no tradicional» de la mención y la teoría «tradicional» de la simulación son sorprendentemente similares" (1984: 127). Clark y Gerrig sólo se oponen a la teoría de la mención terminológicamente, y además debido a que, también ellos, toman el término mención en su sentido restringido y cotidiano.

En principio parece que la mención soluciona el problema más obvio sobre los enunciados irónicos: el hablante no dice realmente lo que parece decir. Lo que hace, según esta teoría, es mencionar, como un eco, anteriores enunciados o sentimientos. La solución es tratar la ironía como una mención ecoica. Sin embargo, mencionar enunciados anteriores no basta para explicar el asunto (Clark y Gerrig, 1984: 125).

Ciertamente, no basta. Pero, como hemos visto, la mención, en el sentido técnico que Wilson y Sperber le dan al término, no alude a la fuerza a un enunciado previo, sino en principio a uno posible: lo mencionado es, ante todo, el significado o pensamiento convencionalmente asociado a él.

Un enunciado irónico hace eco de un pensamiento mediante la mención de un significado que le corresponde. El pensamiento del que se hace eco puede haber sido expresado verbalmente, o bien puede ser una opinión dada, pero esto no es en absoluto necesario. Todo lo necesario es que el pensamiento pueda atribuirse a gente específica, a un tipo específico de gente o a la gente en general (Sperber, 1984: 131-132).

Con esta aclaración de por medio, es natural que, como dicen los propios Clark y Gerrig, "todos los casos de mención irónica puedan reinterpretarse como casos de simulación irónica" (1984: 123). A lo que hay que añadir: y viceversa, siempre que se entienda la mención en su sentido amplio y técnico ${ }^{7}$.

7 El siguiente esquema, en el que meramente se contempla la equivalencia de los términos centrales de cada teoría, simulación y mención, puede completarse con el más exhaustivo de Barbe (1995:50). 
El locutor no $u s a$ el enunciado, lo menciona.

El locutor no usa el enunciado, sólo simula usarlo.

La mención representa el pensamiento mencionado y señala a su responsable, real o posible, como víctima de la ironía.

La simulación representa el pensamiento simulado $\mathrm{y}$ señala al locutor imitado, real o imaginario, como víctima de la ironía.

En definitiva, en la práctica lo mismo resulta una teoría que la otra. Por lo demás, ambas pueden asimilarse al modelo polifónico de Ducrot, ganando en claridad y sin menoscabo de su valor explicativo.

\section{Evaluación general del enfoque polifónico}

Enunciación polifónica, mención y simulación son tres rótulos para un mismo enfoque de la ironía, el cual la caracteriza como un distanciamiento crítico del locutor con respecto a su enunciado. Este enfoque permite explicar algunos aspectos y efectos de la enunciación irónica descuidados por la concepción tradicional de la ironía, según la cual es el tropo mediante el cual se dice lo contrario de lo que realmente se piensa y se significa. La ironía, como toda figura retórica, supondría por tanto una desviación con respecto al lenguaje neutro, la transgresión de la norma(lidad) discursiva, de modo que la expresión irónica (figurada) estaría sustituyendo a otra neutra (normal) equivalente, la cual puede restituirse mediante una traducción. La idea es que toda figura empieza por una transgresión cuya anomalía exige que se traduzca a términos neutros; esta traducción, que enmienda el uso desviado, es la interpretación de la figura (Ricoeur, 1975: 186-194).

Para empezar, el enfoque polifónico refleja en términos discursivos uno de los atributos clásicos de la ironía: la distancia.

La ironía es la perspectiva opuesta a la devoción, a la sublimación de un objeto. Es un "distanciamiento relativamente desapasionado" (Hutcheon, 1994: 41), que permite "recuperar la distancia perdida" (Bozal, 1999: 97). La ironía no es un acto de afirmación ni de negación de lo ironizado, sino un movimiento que "poniéndolo a distancia, descubre que lo que éste dice no es tal" ( $i b:$ 99-100). "La ironía introduce en nuestro conocimiento el relieve y el escalonamiento de la perspectiva" (Jankélévitch, 1964: 21). "Ironizar es ausentarse", dice el poeta ruso Blok (1908: 39). El hablante se libera de la responsabilidad de suscribir el sentido de su discurso; el poder de la ironía "reside en la capacidad de corregir lo subjetivo por lo objetivo: la adhesión a los sentimientos es equilibrada por la distancia crítica" (Schoentjes, 2001: 101).

La objetividad de la ironía consiste en la fragmentación del locutor unitario en varias voces o puntos de vista dentro de la misma enunciación, a alguno de los cuales se opone y critica de manera implícita. El locutor simula comunicar su pensamiento, pero lo que en realidad comunica es tan sólo un pensamiento ajeno, del que se disocia en mayor o menor medida. 
Donde hay ironía, hay desdoblamiento del locutor. En ese desdoblamiento, el listo habla con las palabras del tonto, pero distanciándose de ellas y mostrando su actitud ante esas palabras y ante la situación a la que tan mal se aplican. Mientras el que dice algo en serio lo asume [...], el que dice algo irónicamente se desdobla: achaca esa afirmación (y, con ella, ese punto de vista) a un ser ficticio, a un alter ego ridículo (Reyes, 1994: 56).

La enunciación irónica se distingue de la neutra (no irónica) precisamente por la falta de compromiso del locutor con su discurso. Es un mero pretexto, un simulacro de enunciación cuyo contenido es sólo mencionado para significar una actitud negativa hacia él. El enunciado es presentado como una perspectiva o enunciador absurdo, desautorizado y condenado por su propia irrelevancia. "La ironía condesciende al error no para comprenderlo, sino para destruirlo" (Jankélévitch, 1964: 102).

Abunda con generosidad en el sentido del error para ridiculizarlo: lo arruina no atacándolo de frente, sino indirectamente, caminando a su lado, volviéndose su cómplice. [...] Imitando las falsas verdades, las obliga a desplegarse, a profundizar, a detallar su bagaje, a revelar los defectos que, sin ella, pasarían desapercibidos; hace estallar su falta de sentido, induce al absurdo a refutarse a sí mismo, es decir, lo fuerza a que sea él quien administre la prueba de su imposibilidad (ib.: 99-100).

Esto explica además la manera en que la enunciación irónica señala a su víctima: por medio de su discurso, de la expresión mimética de su pensamiento.

"El objetivo de la ironia es batir al adversario en su propio terreno, fingiendo suscribir sus premisas, sus valores, su manera de razonar, con el fin de exponer su banalidad implícita" (Koestler, The Act of Creation). [...] La ironía aparenta tomarse en serio lo que no aprecia; penetra en el espíritu del juego ajeno para demostrar que sus reglas son estúpidas o perversas (Schoentjes, 2001: 200).

La ironía es un discurso diferido, referido (mencionado), simulado, una farsa de enunciación: quien ironiza representa un papel discursivo, habla como el tipo de locutor al que quiere poner en ridículo. De hecho, como apunta Ballart (1994: 40), la ironía verbal se origina en la comedia griega, en el duelo estereotipado entre la ingenuidad de la víctima (el alazon, un presuntuoso insensato) y el disimulo del irónico (el eiron, quien simula convenir con su oponente para arrastrarlo al absurdo con la complicidad del público).

El simulacro puede describirse en términos polifónicos. El enunciado representa un punto de vista (un enunciador) que, en sí mismo o dado el contexto, resulta absurdo y que, debido a ello y a otras marcas facultativas (entonación, gestos, cursiva, etc.), no puede ser atribuido directamente al locutor. Sin embargo, la verdadera opinión de éste no aparece en el enunciado: "En el enunciado no se expresa ningún punto de vista opuesto al absurdo (no es rectificado por ningún enunciador)" (Ducrot, 1990: 20).

En realidad, el enunciado no se usa para comunicar algo por medio de él, sino acerca de él (Basire, 1985: 141). Así, la "víctima" es en primera instancia el punto de vista (el enunciador), pensamiento o discurso representado por el enunciado, todos ellos entes discursivos, pero también los entes reales - la persona, personas, tipo de personas, publicaciones, instituciones, medios, organismos, etc.- en que el discurso ironizado se encarna y que, por tanto, se identifican con él y lo ejercen. En otras palabras, el discurso puede usarse como un 
signo de sí mismo y, por extensión metonímica (como un índice o sintoma, pues), también de sus usuarios. De ahí que, en la ironía citativa -que, recordemos, Kerbrat-Orecchioni (1980: 122) opone a la no citativa-, el enunciado irónico tenga la propiedad de indicar a su víctima. De ahí, también, la preferencia del discurso irónico por el cliché, el estereotipo, la idea común el chascarrillo o la fraseología representativos.

El locutor irónico, a la vez que se separa de su enunciado, evoca otro locutor (concreto o típico; es decir, un ser de carne y hueso o un mero tipo discursivo) para llenar por osmosis el vacío dejado por él. El enunciado funciona como un índice, un signo metonímico de su posición y origen discursivos.

Con todo, el mayor acierto de este enfoque es que presenta la ironía como un fenómeno de por sí convencional, y no la trasgresión de una convención más general o de distinta naturaleza, lo que permite entenderla como una estrategia discursiva particular y, por tanto, una alternativa de interpretación opuesta al discurso neutro (no irónico).

$\mathrm{La}$ interpretación irónica no corrige una interpretación neutra inconveniente: ambas se sitúan al mismo nivel, como formas alternativas de considerar la relación entre los elementos de la enunciación, "todo enunciado puede entenderse de dos maneras distintas" (Wilson y Sperber, 1992: 62):

a) De modo neutro, cuando el sentido presenta al locutor como responsable del enunciado explícito (cuando el enunciado se usa).

b) De modo irónico, cuando el locutor "hace oír una voz que no es la suya" (Ducrot, 1984: 215) y que expresa un pensamiento absurdo e insostenible (cuando el enunciado se menciona con un matiz despectivo).

Existen dos grandes maneras de comunicarse: una seria y otra no-seria. Hay comunicación seria cuando el locutor se asimila a uno de los enunciadores, es decir, cuando elige un enunciador como su portavoz. [...]

La comunicación no-seria se basa en la simple presentación de los enunciadores, presentación que es vista como significativa por sí misma (Ducrot, 1990: 28-29).

De ahí que no sea del todo justa la observación de Basire (1985: 141) según la cual a la distinción entre sentido literal y sentido figurado le corresponde la distinción entre uso y mención (en la teoría de Wilson y Sperber; uso y simulación, en Clark y Gerrig; asimilación y disimilación del locutor al enunciador, en Ducrot). Pues mientras que la primera oposición supone un tránsito del sentido literal al figurado, las demás se presentan como bifurcaciones interpretativas. No se trata, pues, de pasar por un sentido "normal" incongruente hacia otro derivado. En realidad, se trata de saber qué tipo de discurso o "comunicación" está en juego, y la finalidad de la incongruencia (así como las otras marcas de ironía) es precisamente indicarlo y señalar, asimismo, la vía de interpretación adecuada.

Pues, ¿cómo entender la ironía si no se tratase de una forma convencional de interpretación y discurso? Quienes la describen como una transgresión del discurso convencional, como una interpretación "normal" anómala, han de ver en ella a la fuerza un fenómeno que "no requiere ninguna convención extralingüística ni de ningún otro tipo". Un fenómeno que, por tanto, puede ser explicado recurriendo a los principios y las reglas generales de la conversación y el sistema lingüístico (Searle, 1979: 109); en concreto, suponiendo que consiste en una violación manifiesta de ellos. 
El intérprete advierte la infracción de una norma discursiva. A partir de ahí, trata de restituir la coherencia a la enunciación por medio de una inferencia pragmática. Grice, por ejemplo, describe este proceso de la siguiente manera:

Él ha dicho que $p$; no hay ninguna razón para suponer que no esté observando las máximas, o al menos el principio de cooperación; podría estar cumpliéndolas si pensase que $q$; sabe (y sabe que yo sé que él sabe) que yo me apercibo de la necesidad del supuesto de que piensa que $q$; no ha hecho nada para impedirme pensar que $q$; por lo tanto, pretende que yo piense, $\mathrm{o}$ al menos desea hacerme posible que piense, que $q$; y consiguientemente ha implicado que $q(1975: 521)$.

Visto así, la ironía (la comunicación implícita en general) parece un fenómeno extraordinario y milagroso. Aunque, más bien a la inversa, el prejuicio de considerar que la ironía (y, en general, que pueda comunicarse algo más, o incluso algo distinto, de lo estrictamente contenido en el "mensaje lingüístico") es un fenómeno extraordinario, lleva a describir su interpretación de esta complicada manera. Como si la ironía (y, en general, la comunicación implícita) no fuese un tipo de discurso convencional, un uso habitual e identificable de la enunciación como signo complejo (enunciado y contexto); como si, al contrario, cada vez que el intérprete da con un enunciado irónico hubiera de comportarse como si fuese de nuevo la primera vez, como si se hallase ante una singularidad discursiva $\mathrm{y}$, por tanto, tuviese que improvisar cada vez una estrategia de interpretación nueva para adivinar su auténtico sentido.

Todo lo contrario, al discurso irónico le corresponden una serie de esquemas y de valores propios y plenamente convencionales: la contradicción argumentativa entre el enunciado y el contexto, la disociación entre el locutor y el punto de vista que representa el enunciado, el distanciamiento y la crítica implícita a dicho punto de vista, así como al universo discursivo al que pertenece y a quienes se identifican con ambos, etc. Esto es, no menos convencionales que los propios del discurso neutro (no irónico): la congruencia argumentativa, la responsabilidad del locutor en relación con su enunciado y, en general, su discurso, etc.

El intérprete no se encuentra, pues, con una transgresión discursiva consumada que debe reinterpretar en clave irónica, sino ante dos alternativas de interpretación opuestas e igualmente convencionales. Dos tipos de discurso, dos "maneras de comunicarse", un dilema cuya clave ofrece la misma enunciación como parte de su sentido: la enunciación se presenta como irónica, manifiesta su propia ironía. Así, la transgresión de la ironía es un delito discursivo simbólico, un simulacro cuyo fin es señalar la vía de interpretación adecuada y descartar la incongruente.

La contradicción argumentativa funciona como un auténtico índice: muestra que la enunciación ha de entenderse en sentido irónico, es decir, de acuerdo con el esquema interpretativo de este tipo de discurso. Lo que recuerda la función de los indices que, según Peirce, distinguen otros dos universos discursivos opuestos: el habla que se refiere a la realidad (una noticia periodística, un relato verídico) y la que narra algo ficticio (una novela, una fábula, un cuento).

No se puede distinguir el mundo real de un mundo ficticio mediante ninguna descripción. [...] Esto ilustra la necesidad de indicar que se quiere dar a entender el mundo real, si es eso lo que se quiere dar a entender. [...] Tan sólo un signo dinámico [un índice] puede 
distinguirla de la ficción. Es verdad que ninguna lengua (hasta donde sé) posee una forma particular de hablar que revele que se está hablando del mundo real. Pero no es necesario, pues los tonos y las miradas bastan para revelar cuándo el locutor habla en serio. Estos tonos y estas miradas actúan dinámicamente sobre el oyente, y le hacen tomar el objeto del habla por algo real. Por consiguiente, son los indices del mundo real [...]. Este mundo, al igual que un mundo ficticio, requiere un indice que lo distinga (1931: $\$ 2.337$ ).

El intérprete no necesita inferir el sentido irónico: éste no es un contenido sustancial formulable, sino una manera de considerar la enunciación como signo conjunto (enunciado y contexto), inscrita en la propia enunciación como una etiqueta. Pues dado que un enunciado irónico es igual que ese mismo enunciado dicho de modo neutro, es la enunciación en conjunto la que ha de diferir. Diferencia que, por tanto, radica en el contexto, o, siendo más preciso, en la relación semiótica que, en el marco de la enunciación, se establece entre el enunciado y el contexto.

(8) Una habitación de hotel en León. Domingo. Tres de la tarde. Afuera llueve.

A: - Aquí no hay distracciones.

B: - Tenemos el telediario.

Interpretación irónica secuencial

Entunciado

Interpretación literal

Significado literal: Tenemos el telediario

Sentido literal: "objeción a A"

Transgresión discursiva: el enunciado entra en conflicto con la situación de discurso: A sabe que B detesta la televisión $\mathrm{y}$, sobre todo, el telediario.

\section{Reinterpretación irónica}

Sentido irónico (inverso del literal):

"confirmación de A"

\section{Interpretación irónica alternativa}

\section{Enunciado}

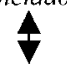

Situación de discurso/ Contexto

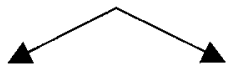

congruente con

el enunciado

(B no tiene nada

contra el telediario)

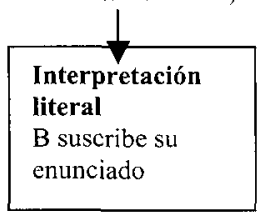

incongruente con el enunciado (B detesta el telediario) $)^{8}$

Interpretación irónica

B no suscribe su enunciado

\section{Digresión final: ¿Convención o relevancia?}

En relación con lo discutido en el apartado anterior, Wilson y Sperber coinciden con la orientación general del enfoque polifónico en que, al igual que cualquier enunciado "convencional", el enunciado irónico recibe directamente una única interpretación. Sin embargo, 
para ellos esto no se debe al carácter también convencional del discurso irónico, sino a la acción compulsiva del principio de relevancia.

Habiendo encontrado una interpretación consistente con el principio de relevancia, el oyente no necesita ir más allá: nunca hay más de una [interpretación]. La primera que se prueba y se muestra consistente con el principio de relevancia es la única interpretación consistente con él, y es la que el intérprete debe elegir (1992: 70).

La interpretación irónica "se da de una manera natural y espontánea", sin que intervenga ninguna convención o estrategia discursiva: "No requiere de convenciones retóricas o de aprendizaje particulares" (ib.: 61-62).

Ahora bien, dada su definición del principio de relevancia, Wilson y Sperber no sólo niegan el convencionalismo del discurso irónico, sino en realidad el de todo tipo de discurso. No es que la interpretación irónica se oponga a una interpretación convencional; más bien, no hay lugar para interpretaciones convencionales, sino únicamente para interpretaciones relevantes.

La interpretación relevante es la más coherente, la que armoniza mejor el enunciado y el contexto (en términos de Wilson y Sperber, la que ofrece más "efectos contextuales"). Nada habría que objetar si la relevancia se definiera como el efecto de una ley convencional, y no de una especie de principio natural o psicológico.

Lo que nosotros afirmamos es que todos los seres humanos tienden automáticamente hacia el procesamiento de información más eficiente que sea posible. Esto es así tanto si son conscientes de ello como si no. [...] El objetivo cognitivo concreto de un individuo en un determinado momento siempre es un ejemplo de un objetivo más general: maximizar la relevancia de la información procesada (Sperber y Wilson, 1986: 66).

Toda interpretación es elegida (o, más bien, acogida) por ser la más relevante. Y es la más relevante porque es la más eficiente, la que produce un mayor rendimiento informativo. $\mathrm{Y}$ es sin duda la que produce un mayor rendimiento informativo porque, de no ser así, no habría sido la elegida - puesto que "todos los seres humanos tienden automáticamente hacia el procesamiento de información más eficiente que sea posible [...] tanto si son conscientes de ello como si no", ya que "la cognición humana tiende a maximizar la relevancia" (2004: 608). De modo que la propia interpretación prueba la relevancia que, supuestamente, la respalda y consolida. Así, pues, ¿es la interpretación relevante de por sí y por eso resulta elegida de manera automática e inconsciente? ¿O es el hecho de resultar elegida lo que la hace (o al menos lo que hace que se proclame que es) relevante? En realidad, el principio de relevancia, por el mismo hecho de que justifica y explica toda interpretación, carece de un auténtico valor explicativo. Es como uno de esos dogmas que, para el creyente, lo explican todo, mientras que para el hombre sin fe no tienen sentido?.

La circularidad del principio de relevancia es una consecuencia del carácter puramente convencional del lenguaje. Lo único que sigue quien interpreta un enunciado es una conven- 
ción, la cual certifica un razonable margen de acuerdo en la interpretación. La interpretación "correcta" del enunciado está más allá de cualquier consideración experimental o científica, pues no es más que un hecho convencional, una institución. En el sentido de que es la propia concordancia en la interpretación la que establece su normalidad y, por tanto, la que sienta la norma. En otras palabras, la interpretación "correcta" es siempre (o debería serlo) la más conveniente: en la que conviene el mayor número de hablantes $\mathrm{o}$, al menos, el criterio de aquellos hablantes con mayor peso específico (los "expertos"). Dada la naturaleza convencional del lenguaje, su corrección no puede ser otra cosa que una cuestión democrática.

Ésta es la razón por la que una interpretación puede probar su corrección y, al mismo tiempo, dar testimonio de la norma que la respalda ${ }^{10}$.

Por supuesto, podemos ponerle un nombre a la convención (relevancia, principio de cooperación, facultad lingüística...), pero con ello aún no hemos explicado nada, salvo la obviedad de que quienes la comparten proceden de acuerdo con ella y, por tanto, de una manera uniforme $y$, aparentemente, "automática", como si se tratase de una genuina propiedad, un rasgo de diseño o designio.

En el fondo, no hay nada que explicar, al menos en el sentido más ambicioso del término. Sentido en que, por ejemplo, se expresan Wilson y Sperber: "Un tratamiento adecuado de la ironía debería aportar no sólo descripciones, sino explicaciones" (1992: 57), y no de cualquier tipo, sino "en términos cognitivamente realistas" (2004: 608). Ambición que prolonga la ya profesada y confesada por Grice: "Soy lo suficientemente racionalista como para desear encontrar una base que subyazca a estos hechos, innegables como son; desearía poder concebir el tipo usual de práctica conversacional no meramente como algo que todos o muchos de nosotros seguimos de hecho, sino como algo que es razonable que nosotros sigamos, como algo de lo que no tendríamos que apartarnos" (1975: 519).

Lo primordial es la existencia "innegable" de una práctica discursiva que se muestra y se apoya en sí misma, que es su propio criterio de corrección y cuyo sentido persiste en la medida en que se acepta y se repite de manera "automática e inconsciente"; una práctica convencional que la lingüística y la pragmática deben analizar, y a cuya comprensión propiamente lingüística (en el sentido amplio de la palabra: como fenómeno del lenguaje) no contribuye en absoluto una teoría de ambiciones psicológicas -"a cognitive psychological theory" (Wilson y Sperber, 2004: 625). No se trata, pues, de oponer convención a relevancia, sino de mostrar la naturaleza convencional de la segunda.

Una teoría pragmática no ingresa en un orden superior de excelencia científica por estar salpimentada de terminología psicológica ("input, efectos cognitivos, esfuerzo de procesamiento"); no deja de ser una teoría pragmática, ciertamente con un sabor peculiar, pero nada más que un sabor, en absoluto nutritivo. En otras palabras, quien, partiendo de los hechos empíricos, quiera trascender su análisis conceptual, quien quiera además profundizar hasta "encontrar una base" todavía más firme (psicológica, biológica, etnológica, antropológica, etc.) se expone, como los arqueólogos del poema de Auden, a hablar de algo "concerning

10 Igual que el resultado correcto de $7+7$ no depende de ningún experimento, sólo puede ser 14 . Este resultado es el criterio de que quien ha calculado ha seguido de hecho la regla convencional de la suma. Si alguien nos diera un resultado distinto, diríamos que ha sumado mal, que no ha sumado de acuerdo con la regla, y así como en ningún caso nos haría dudar de que $7+7=14$, tampoco sería fácil convencerlo de ello sin recurrir a un argumento de fuerza tal que así es como todos sumamos. En sí, la regla es convencional, pero para quien la aplica ejerce una determinación tan firme que le parece actuar de modo automático e inconsciente. 
which he has not much/to say that he can prove:/ the lucky man!/ Knowledge may have its purposes, / but guessing is always/ more fun than knowing".

\section{Referencias bibliográficas}

Attardo, S. (2000): "Irony as relevant inappropiateness", Journal of Pragmatics, 32, págs. 793-826. Ballart, P. (1994): Eironeia: la figuración irónica en el discurso literario moderno. Barcelona, Quaderns Crema.

Barbe, K. (1995): Irony in Context. Amsterdam/Philadelphia, John Benjamins.

Basire, B. (1985): "Ironie et métalangage", DRLAV, 32, págs. 129-150.

Berrendoner, A. (1981): Elementos de pragmática lingüística. Buenos Aires, Gedisa, 1987.

Blok, A. (1908): "Ironía". En Un pedante sobre un poeta y otros escritos. Barcelona, Barral, 1971, págs. $37-42$.

Booth, W. C. (1974): A Rhetoric of Irony. Chicago, The University of Chicago Press.

Bozal, V. (1999): Necesidad de la ironia. Madrid, Visor.

Clark, H. H. y R. J. Gerrig (1984): "On the Pretense Theory of Irony", Journal of Experimental Psychology: General, Vol. 113, 1, págs. 121-126.

Ducrot, O. (1984): El decir y lo dicho: polifonía de la enunciación. Barcelona, Paidós, 1986.

Ducrot, O. (1989): Logique, structure, énonciation. Paris, Les Éditions de Minuit.

Ducrot, O. (1990): Polifonía y argumentación. Universidad del Valle-Cali.

Grice, P. (1975): “Lógica y conversación”. En Valdés Villanueva, L. M. (ed.) (1991): La búsqueda del significado: lecturas de flosofia del lenguaje. Madrid, Tecnos, págs. 511-530.

Hutcheon, L. (1994): Irony's Edge: the Theory and Politics of Irony. London, Routledge.

Jankélévitch, V. (1964): L'ironie. Flammarion.

Jorgensen, J., Miller, G. A. y D. Sperber (1984): "Test of the mention theory of irony", Journal of Experimental Psychology: General, Vol. 113, 1, págs. 112-120.

Kerbrat-Orecchioni, C. (1977): La connotation. Lyon, Presses Universitaires de Lyon.

Kerbrat-Orecchioni, C. (1980): "L'ironie comme trope", Poétique, 41, págs. 108-127.

Kerbrat-Orecchioni, C. (1986): L'implicite. Paris, Armand Colin.

Kundera, M. (1986): El arte de la novela. Barcelona, Tusquets, 1987.

Muecke, D. C. (1982): Irony and the Ironic. London and New York, Methuen.

Peirce, C. S. (1931): Collected Papers, Vol. I: Principles of Philosophy. Massachussets, The Belknap Press of Harvard University Press.

Reyes, G. (1994): Los procedimientos de cita: citas encubiertas y ecos. Madrid, Arco/Libros.

Reyes, G. (2002): Metapragmática: lenguaje sobre lenguaje, ficciones, figuras. Valladolid, Universidad de Valladolid.

Ricoeur, P. (1975): La metáfora viva. Madrid, Trotta, 2001.

Schoentjes, P. (2001): Poétique de l'ironie. Paris, Éditions du Seuil.

Searle, J. (1979): "Metaphor". En Ortony, A. (ed.) (1993): págs. 83-111.

Sperber, D. (1984): "Verbal Irony: Pretense or Echoic Mention?", Journal of Experimental Psychology: General, Vol. 113, 1, págs. 130-136.

Sperber, D. y D. Wilson (1986): La relevancia. Madrid, Visor, 1994.

Williams, J. P. (1984): "Does mention (or pretense) exhaust the concept of irony?", Journal of Experimental Psychology: General, Vol. 113, 1, págs. 127-129.

Wilson, D. y D. Sperber (1992): "On verbal irony", Lingua, 87, págs. 53-76.

Wilson, D. y D. Sperber (2004): "Relevance Theory". En Horn, L. y G. Ward (eds.) (2004): Handbook of Pragmatics. Oford, Blackwell, págs. 607-632. 